\title{
Experimental determination of the hysteretic behaviour of soil-water retention curve of silty sands
}

\author{
Ludwig Angerer ${ }^{1, a}$, Emanuel Birle ${ }^{1}$ \\ ${ }^{1}$ Zentrum Geotechnik, Department of Civil Engineering, Technical University Munich, Baumbachstrasse 7, 81245 Munich, Germany
}

\begin{abstract}
Shear behaviour of unsaturated silty sands is closely linked to the soil-water retention curve (SWRC). The SWRC depends beside the pore structure mainly on the hydraulic path. It hence shows hysteretic behaviour for wetting and drying cycles. This paper presents the results of the experimental determination of the boundary drying and wetting curve for two silty sands. The measurements were carried out using tensiometers at low suctions and the dew point method at high suctions. The influence of water content during compaction was studied by measuring the boundary drying and wetting curves for one silty sand compacted at two different water contents. The experimental results were compared to the predictions of 3 empirical models. The study showed that all models compare well to the experimental results for water contents above the residual water content. A modification was suggested to improve the performance at low water contents.
\end{abstract}

\section{Introduction}

The soil-water retention curve (SWRC) represents a useful function to predict constitutive behaviour of unsaturated soils. So it is e.g. well accepted to relate the SWRC to the increase of shear strength of unsaturated soils compared to the saturated state $[1,2,3,4,5]$. Beside the pore structure, the SWRC is mainly dependent on the hydraulic path and shows a hysteretic behaviour. That means that at the same water content the suction during wetting processes is less than during drying process.

It is common practice to determine the boundary drying curve experimentally while usually less effort is made to measure the boundary wetting curve [6]. The hysteretic behaviour is then often predicted with empirical or physically based models $[7,8,9,10,11]$.

The present investigations are carried out as a part of the examination of slope stability of railway embankments out of silty sands. Since suction and hence shear strength can decrease significantly during wetting processes special emphasis is put on the determination of the hysteretic behaviour of the SWRC of silty sands. For this purpose the boundary drying curves as well as the boundary wetting curves of two statically compacted silty sands are measured in the laboratory. Furthermore, to study the influence of the water content during compaction, the hysteresis of one silty sand is experimentally determined for two compaction water contents. The measurements are carried out using tensiometers at low suctions and the dew point method at high suctions, as described in $[6,12]$.

Based on the results of the experimental studies, three empirical models $[7,10,11]$ are tested with respect to a

\footnotetext{
a Ludwig Angerer: l.angerer@tum.de
}

suitable prediction of the boundary wetting curve. Presupposing the boundary drying curve is known.

\section{Experimental investigations}

\subsection{Soil properties}

The paper examines the SWRC of two silty sands obtained from a railway embankment in Germany. Disturbed and undisturbed soil samples were collected and tested for particle size distribution, specific gravity, in-situ void ratio, in-situ water content and classified by the United Soil Classification System (USCS). Prior to testing the sands were passed through a $4 \mathrm{~mm}$ sieve. Both soil samples were silty sands (SM) with fine content of $28 \%$ and $35.6 \%$, respectively. The particle size distributions of both silty sands are shown in Figure 1. The USCS texture, index properties and in-situ conditions are summarized in Table 1.

Table 1. Index properties of the soils and in-situ conditions

\begin{tabular}{|c|c|c|c|c|c|c|c|}
\hline \multirow{2}{*}{ Name } & \multirow{2}{*}{ USCS } & \multicolumn{3}{|c|}{$\begin{array}{c}\text { Particle size } \\
\text { distribution by weight }\end{array}$} & \multirow{2}{*}{$\begin{array}{l}\text { Gs } \\
{[-]}\end{array}$} & \multirow{2}{*}{$\begin{array}{c}\text { e } \\
{[-]}\end{array}$} & \multirow{2}{*}{$\begin{array}{c}\mathbf{w} \\
{[\%]}\end{array}$} \\
\hline & & $\begin{array}{l}\text { Clay } \\
{[\%]}\end{array}$ & $\begin{array}{l}\text { Silt } \\
{[\%]}\end{array}$ & $\begin{array}{l}\text { Sand } \\
{[\%]}\end{array}$ & & & \\
\hline Sand 1 & SM & 5 & 23 & 70 & 2.66 & 0.56 & 14.25 \\
\hline Sand 2 & SM & 15.6 & 20 & 64 & 2.67 & 0.62 & 4.75 \\
\hline
\end{tabular}




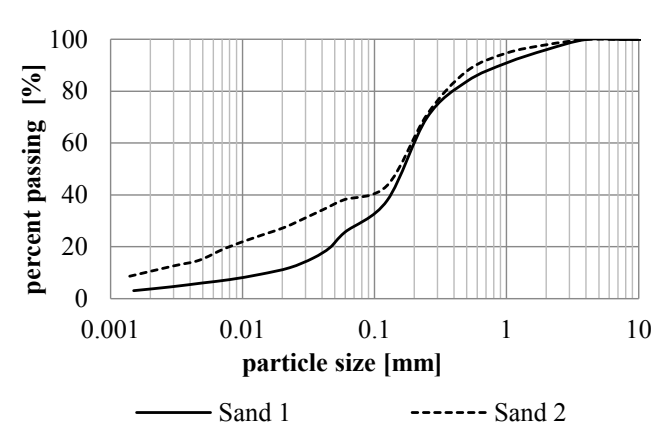

Figure 1. Particle size distribution curves of the silty sands

\subsection{Testing methods and sample preparation}

Suction was obtained by direct measurements with tensiometers, manufactured by UMS, at low suctions $(<100 \mathrm{kPa})$ and by indirect measurements with the dew point method at high suctions $(>1000 \mathrm{kPa})$. The dew point method was conducted by using the Decagon devices WP4 and WP4C. According to [6] osmotic suction can be neglected for the present soils. For this reason it is assumed to measure only matric suction with both methods.

The boundary drying and wetting curves were obtained from statically compacted specimens. Static compaction was carried out to approximately obtain the in-situ soil fabric at the in-situ void ratio at the in-situ water content. Since Sand 1 seemed to be in a relatively wet state an additional set of drying and wetting curve were measured in which the water content during compaction was decreased from $\mathrm{w}_{\text {comp. }}=14.25 \%$ to $\mathrm{w}_{\text {comp. }}=5 \%$.

\subsubsection{Sample preparation for tensiometers}

The soil samples for the measurements with tensiometers were statically compacted in two layers directly into 8 suction cells with a diameter of $10 \mathrm{~cm}$ and a height of $3.5 \mathrm{~cm}$ as shown in Figure 2. Compaction was carried out by a hydraulic press with one piston compacting the soil on the top. The interfaces between the layers were roughened carefully.

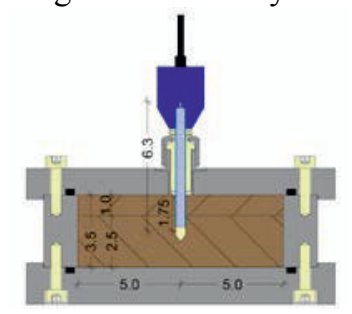

Figure 2. Suction cell with tensiometer

In order to determine the drying curves, the samples were initially placed into a water basin for at least 3 days. For that, the top caps of the cells were removed and the bottoms were replaced with filter plates. Saturation was assumed to be complete when no more change in weight was observed. After reaching the maximum degree of saturation (quasi-saturation) the samples were closed for one day to achieve homogeneity and placed in a climate chamber with a controlled air temperature of $20^{\circ} \mathrm{C}$ and a relative humidity of $60 \%$. Afterwards first measurements were carried out. Subsequently the specimens were air dried stepwise to the desired water content and measurements were performed. Prior each measurement a homogenisation time of 2 - 5 days was provided.

The wetting curves were obtained by initially desaturating the samples under a heating lamp for several days until no more changes in weight was observed. Subsequently water was carefully added until the desired water content was reached and measurements were carried out. The time of homogenisation was about $2-7$ days.

\subsubsection{Sample preparation for dew point method}

The soil samples for the measurements with the chilled mirror dew-point hygrometers were statically compacted in one layer of $0.6 \mathrm{~cm}$ height into sample cups with a diameter of $4 \mathrm{~cm}$ and a height of $1.2 \mathrm{~cm}$. The sample cups are provided by Decagon for WP4 measurements.

To obtain the drying curves the samples were initially wetted by carefully adding water with a pipette. Subsequently the specimens were dried under a heating lamp stepwise to the desired water content and measurements were carried out. For each step a homogenisation time of 3 - 7 days was provided.

To determine the wetting curves the samples were initially desaturated by a heating lamp for several days until no more changes in weight was observed. Subsequently water was added until the desired water content was reached. After a homogenisation time of 3 - 7 days measurements were carried out.

\subsection{Results}

The measured data were used to estimate the soil suction over the entire range of $0 \mathrm{kPa}$ to $1 \cdot 10^{6} \mathrm{kPa}$ by using the Fredlund and Xing equation [13]. The best-fit parameters were obtained by a nonlinear regression analysis. The results for all sands and water contents during compaction are shown in Figures 3 to 5 .

Table 2. Air entry values $\psi_{\mathrm{AE}}$ and residual conditions $\psi_{\mathrm{r}}$

\begin{tabular}{|c|c|c|c|c|}
\hline SWRC & $\begin{array}{c}\psi_{\mathrm{AE}} \\
{[\mathbf{k P a}]}\end{array}$ & $\begin{array}{l}\mathbf{w}_{\max } \\
{[\%]}\end{array}$ & $\begin{array}{c}\psi_{\mathrm{r}} \\
{[\mathrm{kPa}]}\end{array}$ & $\begin{array}{c}\mathbf{w r}_{\mathbf{r}} \\
{[\%]}\end{array}$ \\
\hline Sand $1\left(\mathrm{w}_{\text {comp. }}=14.25 \%\right)-\mathrm{d}$ & 1.0 & 19.0 & 70 & 4.2 \\
\hline Sand $1\left(w_{\text {comp. }}=14.25 \%\right)-\mathrm{w}$ & 0.8 & 19.0 & 45 & 3.6 \\
\hline Sand $1\left(w_{\text {comp. }}=5 \%\right)-d$ & 1.9 & 17.7 & 22 & 7.0 \\
\hline Sand $1\left(\mathrm{w}_{\text {comp. }}=5 \%\right)-\mathrm{w}$ & 1.1 & 17.7 & 19 & 5.4 \\
\hline Sand 2 - d & 1.9 & 22.0 & 25 & 7.3 \\
\hline Sand 2 - w & 0.9 & 21.9 & 20 & 5.3 \\
\hline
\end{tabular}

All SWRCs show a similar behaviour with a flat transition zone. The air entry values are between approximately $0.8 \mathrm{kPa}$ and $1.9 \mathrm{kPa}$ and residual conditions, as described by [4], are reached at suctions 
higher than approximately $19 \mathrm{kPa}$ to $70 \mathrm{kPa}$ (Table 2). The water content at quasi-saturated conditions $\mathrm{w}_{\max }$ remains constant for each drying and wetting cycle, whereas the residual water content of the wetting branch is lower than the one of the drying branch.

In a semilogarithmic scale the shift between the boundary drying curve and the boundary wetting curve seems to be approximately parallel over the entire range of water content. At the inflection point of the boundary wetting curve the matric suction decreases about $5 \mathrm{kPa}$ to $20 \mathrm{kPa}$ compared to the boundary drying curve.

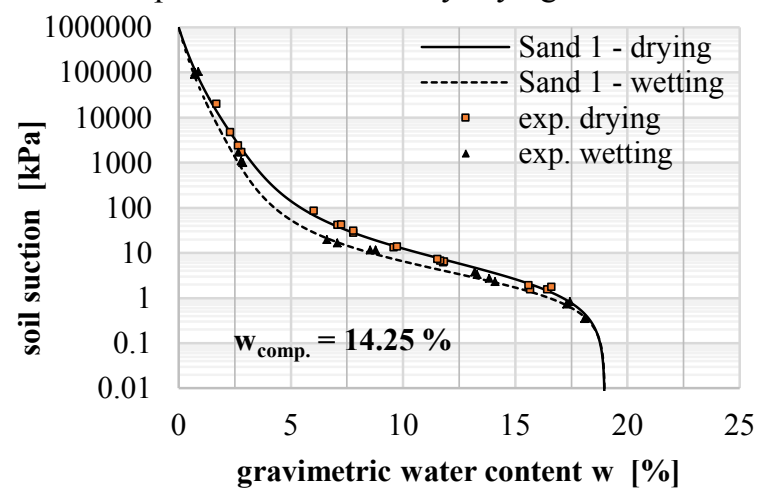

Figure 3. SWRCs of Sand $1\left(\mathrm{w}_{\mathrm{comp}} .=14.25 \%\right)$

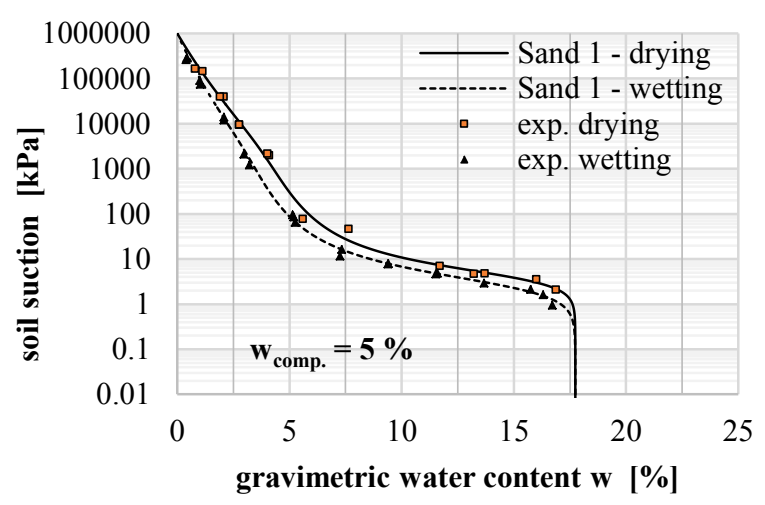

Figure 4. SWRCs of Sand $1\left(\mathrm{w}_{\mathrm{comp}}=5 \%\right)$

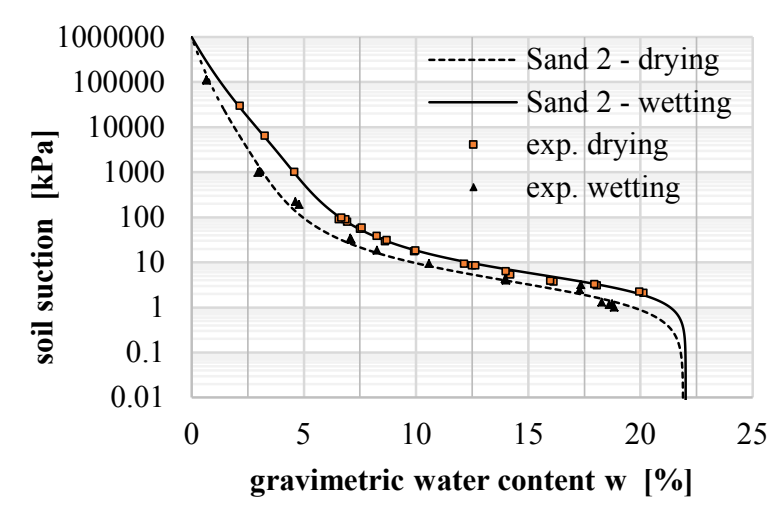

Figure 5. SWRCs of Sand 2

As can be seen by comparing the measured SWRCs of Sand 1 static compaction at different water contents influences the soil fabric of the tested samples. Figure 6 reveals that the compaction water content affects the water content at quasi-saturated conditions. That can be explained with the increase of inter-aggregate pores with decreasing compaction water content $[14,15]$. The water in the comparatively large inter-aggregate pores drains as soon as the suction cells are lifted from the water basin and hence the measurable maximum water content at quasi-saturated conditions decreases. The air entry value and the transition zone remain mainly unaffected from the compaction water content. Slight differences in this range are supposed to be caused by small inhomogeneities within the samples. However, the residual zone seems to be unexpectedly influenced by the compaction water content. The measured suctions are higher for samples compacted at a water content of $5 \%$ than for samples compacted at $14.25 \%$, what is in contrast to the results obtained by [14]. The reasons for this cannot be clearly identified but it is assumed that due to the preferential building of aggregates at lower water contents and the comparatively small measures of the sample cups of the WP4 devices the fine content differs between the tested samples. Therefore, the samples compacted at water contents of $5 \%$ could comprise a slightly higher fine content than the samples compacted at $14.25 \%$ which leads to higher suctions. Despite the dependency on water content during compaction the drying and wetting curves of Sand 1 show a similar hysteretic behaviour and for this both sets of curves are taken into account for testing the three empirical models for the prediction of hysteretic behaviour.

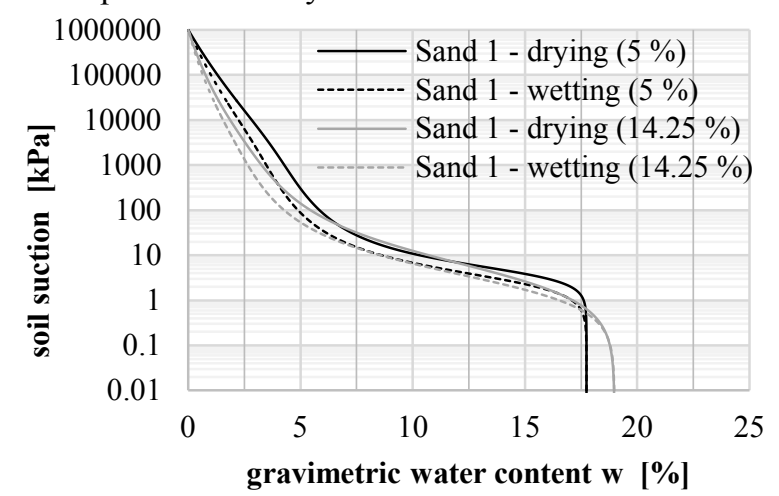

Figure 6. Comparison of the Fredlund and Xing best-fit curves of measured data of Sand 1 ( $\mathrm{w}_{\text {comp. }}$ )

\section{Prediction of hysteretic behaviour}

\subsection{Pham et al. (2003) model}

The Pham et al. (2003) model [10] uses the following equation to describe the SWRC:

$$
w(\psi)=\frac{w_{u} b+c \psi^{d}}{b+\psi^{d}}
$$

Based on the best-fit parameters $d_{d}, b_{d}, w_{u}$ and $c$ of the drying branch, they suggested approximate locations of two suctions on the wetting branch, which should be measured to predict the entire boundary wetting curve:

$$
\begin{gathered}
\psi_{1 w}=\left(\frac{b_{d}}{10}\right)^{\frac{1}{d_{d}}} \\
\psi_{2 w}=\psi_{1 w}-2\left\{\left[\frac{b_{d}\left(w_{u}-w_{1 w}\right)}{w_{1 w}-c}\right]^{\frac{1}{d_{d}}}\right\}-b_{d} \frac{1}{d_{d}}
\end{gathered}
$$


From those two points the parameters for the boundary drying curve $\mathrm{d}_{\mathrm{w}}$ and $\mathrm{b}_{\mathrm{w}}$ can be calculated:

$$
\begin{gathered}
d_{w}=\frac{\log \left[\frac{\left(w_{1 w}-c\right)\left(w_{u}-w_{2 w}\right)}{\left(w_{u}-w_{1 w}\right)\left(w_{2 w}-c\right)}\right]}{\log \left(\frac{\psi_{2 w}}{\psi_{1 w}}\right)} \\
b_{w}=\frac{\psi_{1 w}^{d_{w}}\left(w_{1 w}-c\right)}{w_{u}-w_{1 w}}
\end{gathered}
$$

The parameters $\mathrm{c}$ and $\mathrm{w}_{\mathrm{u}}$ are the same for both the drying curves and wetting curves.

\subsection{Pham et al. (2005) model}

The Pham et al. (2005) model [7] presented a method to predict the above mentioned parameter of equation (1) of the boundary drying curve without any further measurements. Furthermore they added the Fredlund and Xing correction factor [13] to the equation (1) in order to achieve a better prediction of the behaviour of the SWRC in the residual zone:

$$
\begin{aligned}
& w(\psi)=\frac{w_{\mathrm{u}} \mathrm{b}+\mathrm{c} \psi^{\mathrm{d}}}{\mathrm{b}+\psi^{\mathrm{d}}} \cdot\left[1-\frac{\ln \left(1+\frac{\psi}{\psi_{\mathrm{r}}}\right)}{\ln \left(1+\frac{10^{6}}{\psi_{\mathrm{r}}}\right)}\right] \\
& \mathrm{d}_{\mathrm{w}}=\frac{\mathrm{d}_{\mathrm{d}}}{\mathrm{R}_{\mathrm{SL}}}
\end{aligned}
$$

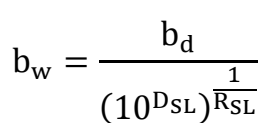

In equation (7) $R_{S L}$ represents the ratio of the slopes of the boundary wetting and boundary drying curves in semilogarithmic coordinate system. In equation (8) $\mathrm{D}_{\mathrm{SL}}$ is the distance between both boundary curves. Based on a study of numerous soils the parameters for sands can be set to $\mathrm{R}_{\mathrm{SL}}=1.0-2.0$ and $\mathrm{D}_{\mathrm{SL}}=0.2-0.35$ [7].

[7] suggested to estimate the residual suction with:

$$
\psi_{\mathrm{r}}=(2.7 \cdot \mathrm{b})^{\frac{1}{\mathrm{~d}}}
$$

The parameters $\mathrm{c}$ and $\mathrm{w}_{\mathrm{u}}$ remain, similar to the Pham et al. (2003) model, constant for the drying and wetting branch.

\subsection{Fredlund et al. (2011) model}

As the boundary drying curve and the boundary wetting curve seem to be congruent to each other, Fredlund et al. (2011) [11] suggested to adjust the best-fit parameter $a_{d}$ of the Fredlund and Xing equation, which controls the shift of the SWRC in direction of the suction in order to predict the boundary wetting curve:

$$
\mathrm{a}_{\mathrm{w}}=\mathrm{a}_{\mathrm{d}} \cdot 10^{-\frac{\mathrm{x}}{100}}
$$

The exponent $x$ in equation (10) represents the shift of the inflection point between the boundary drying and wetting curve expressed in percent of a log-cycle. For sands [11] suggest values for $\mathrm{x}$ varying between $15 \%$ and $35 \%$. The best-fit parameters $m_{d}$ and $n_{d}$ of the boundary drying curve remain constant for the wetting curve.

\subsection{Results and discussion}

The results of the three models are shown in Figure 7 together with the Fredlund and Xing best-fit curves of the measured data.

The Pham et al. (2003) model compares very well to the Fredlund and Xing curves for water contents higher than the residual water content, which is controlled by the parameter c. The asymptotic behaviour of the model cannot reproduce the measured data at water contents bellow c. This could be overcome by introducing the Fredlund and Xing correction factor. A disadvantage is the necessity of experimental determination of two points on the boundary drying curve to obtain the model parameters.

For the Pham et al. (2005) model the parameter $\mathrm{R}_{\mathrm{SL}}=1.0$ was chosen as the measured boundary drying curves turned out to be approximately parallel to the boundary wetting curves. The parameter $\mathrm{D}_{\mathrm{SL}}$ was set to 0.2 , as suggested by [7] for sands. Those parameters yielded the best results. The model fits the measured data for water contents above the residual water content very well but tends to slightly overestimate the wetting curve. However, due to the fact that the parameter $\mathrm{c}$ remains constant for both, the drying and the wetting curve, the model cannot predict hysteretic behaviour at water contents bellow the residual water content properly. This can be overcome by modifying the parameter $\mathrm{c}$ as it is shown in chapter 4.

The results of the Fredlund et al. (2011) model are shown in Figure 7 for $\mathrm{x}=15 \%, 25 \%$ and 35 in order to cover a possible area in which the boundary wetting curve can occur. The measured data lie for high water contents between the predicted boundary curves $(\mathrm{x}=15 \%$ and $35 \%)$ but are overestimated for water contents approximately bellow the residual water content. The model is not able to predict the boundary wetting curve with a single value of $x$ but gives a good estimation for expectable suctions.

\section{Modified Pham et al. (2005) model}

In order to achieve a suitable estimation of the boundary wetting curve for low water contents with the Pham et al. (2005) model, the parameter $\mathrm{c}_{\mathrm{w}}$ of the wetting curve has to differ from the best-fit parameter $c_{d}$ of the drying curve. As shown in Table 2 the residual water content $\mathrm{w}_{\mathrm{r}}$ of the wetting curve tends to decrease compared to the drying branch. The SWRC is shifted in this area towards lower water contents. The difference of the residual water contents seem to be of the same order as the shift of suction in a semilogarithmic coordinate system. This can be considered by modifying the parameter $\mathrm{c}_{\mathrm{w}}$ for the wetting curve of the Pham et al. (2005) model:

$$
\mathrm{c}_{\mathrm{w}}=\mathrm{c}_{\mathrm{d}} \cdot\left(1-\mathrm{D}_{\mathrm{SL}}\right)
$$




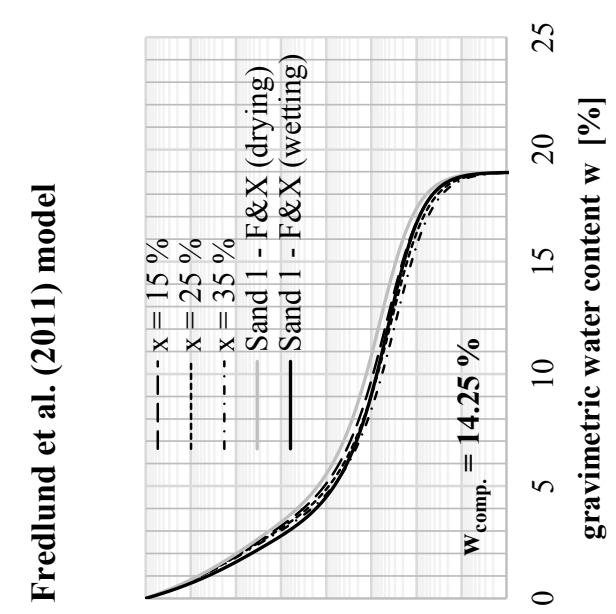

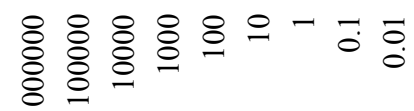

[r.dY] uo!̣ns I!OS

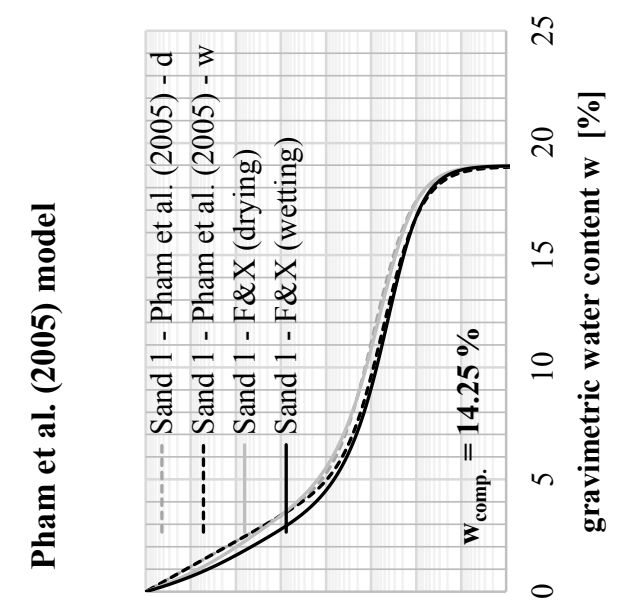

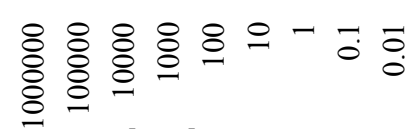

[в dy] uo!̣ons I!os

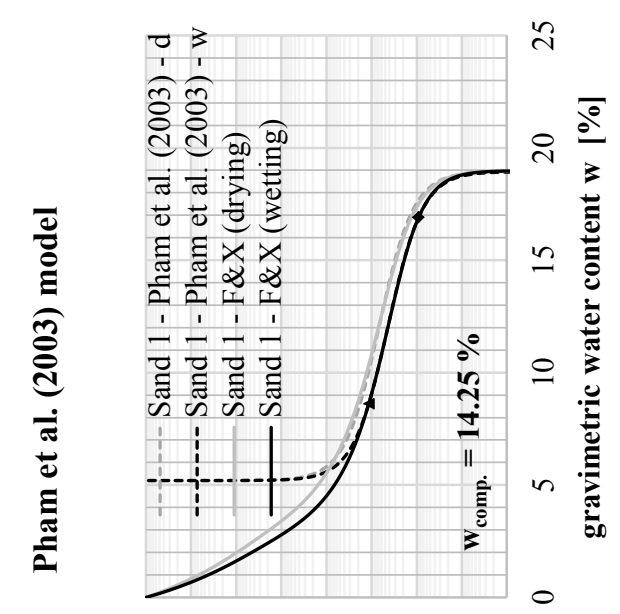

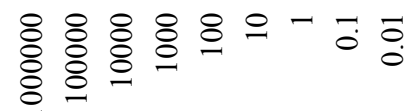
[Bdy] uo!̣ons I!os

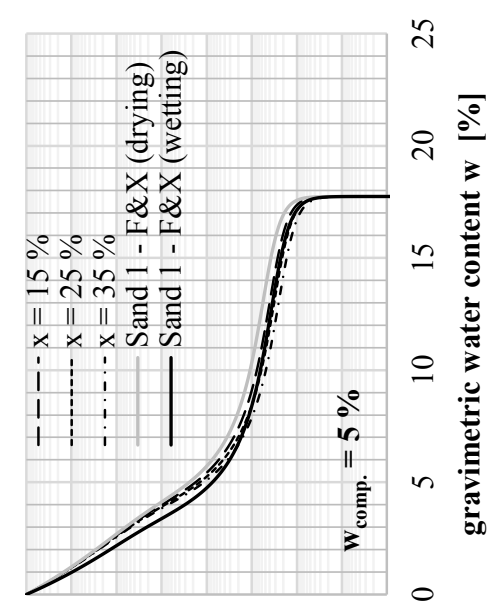

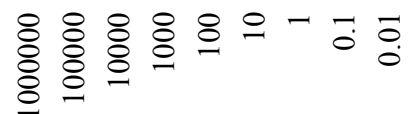

[rdy] uo!̣ons I!Os

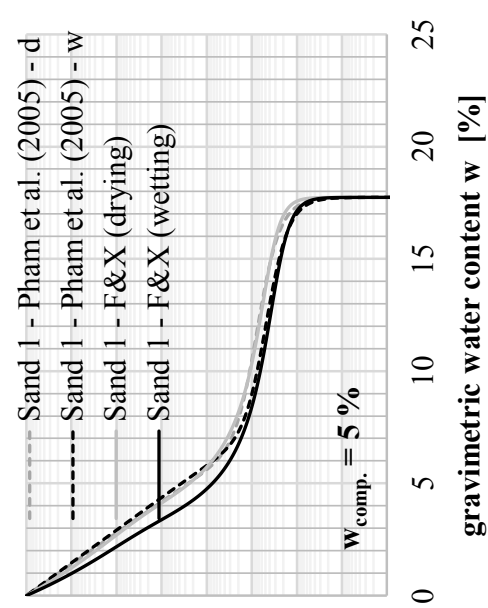

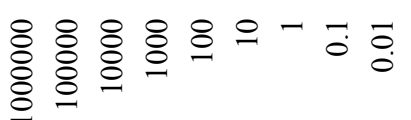

[в dy] uo!̣ons I!os

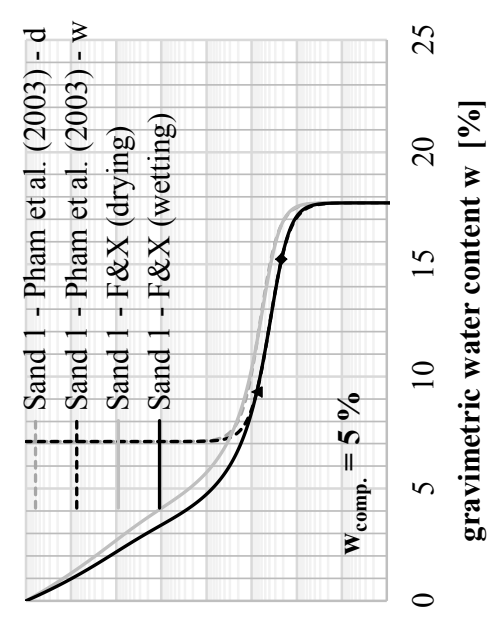

\&: \& \& $80-\overline{0}$

[rdy] uọ̣ons I!os

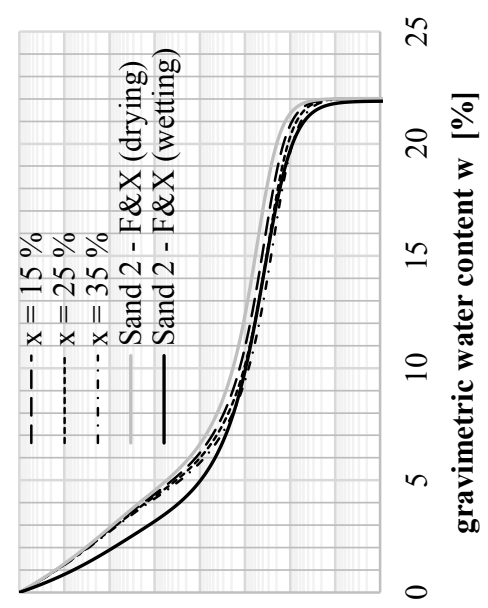

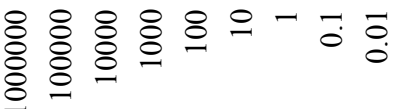

[rdy] uo!̣ons I!os

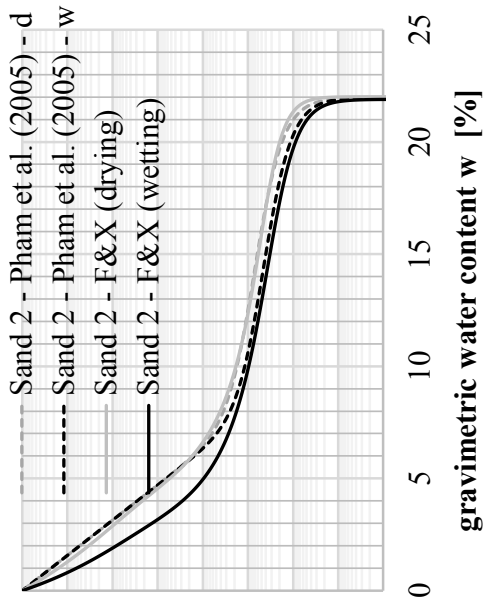

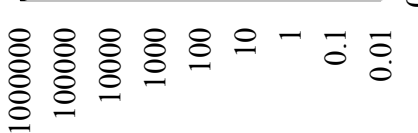

[в dy] uọpons I!os

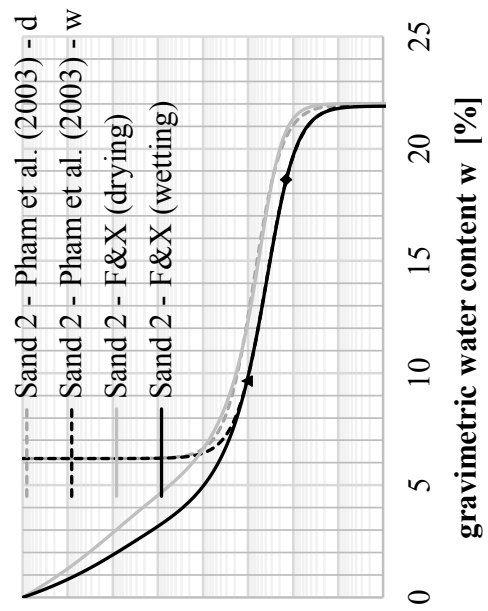

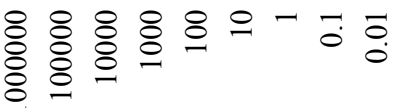

[rdy] uo!̣ons I!os

Figure 7. Results of the models of Pham et al. (2003), Pham et al. (2005) and Fredlund et al. (2011) 
The results of the modified model are shown in Figures 8, 9 and 10. They indicate that hysteretic behaviour of the tested silty sands at low water contents can be satisfactorily predicted by adjusting the parameter $\mathrm{c}_{\mathrm{w}}$ as suggested in equation (11).

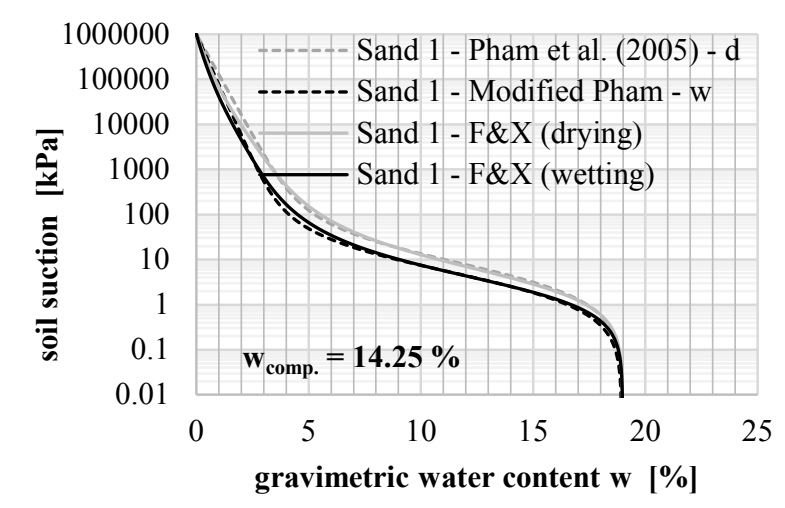

Figure 8. Modified Pham et al. (2005) model for Sand 1 $\left(\mathrm{w}_{\text {comp. }}=14.25 \%\right)$

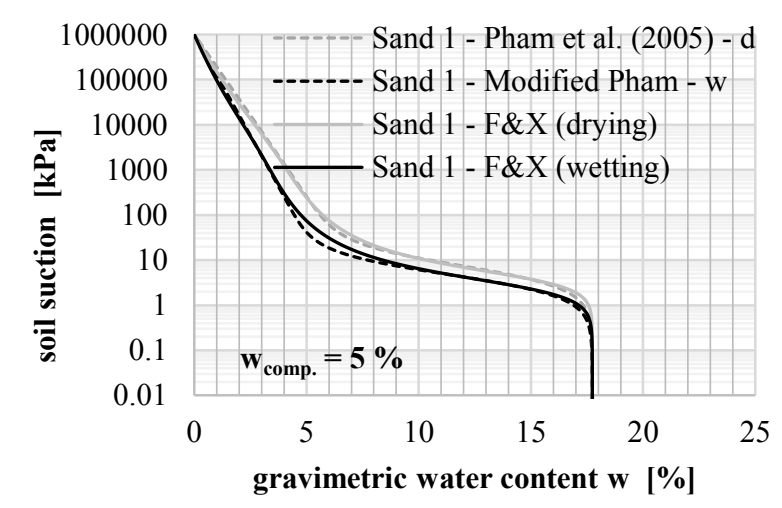

Figure 9. Modified Pham et al. (2005) model for Sand 1 $\left(\mathrm{w}_{\text {comp. }}=5 \%\right)$

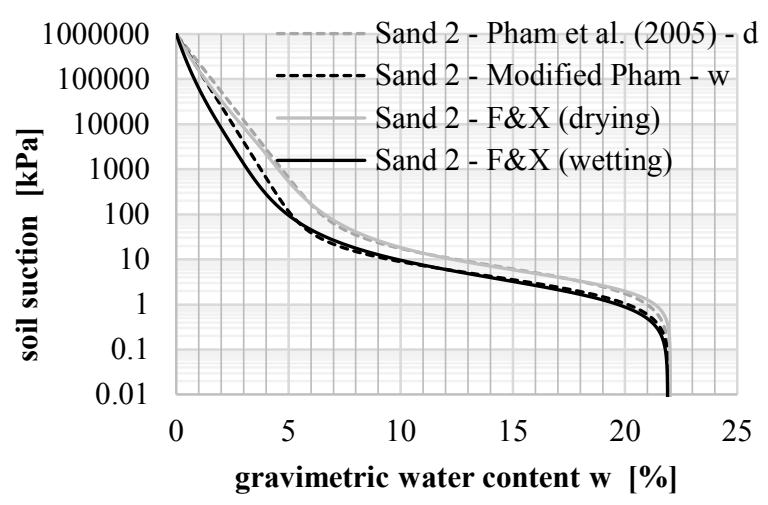

Figure 10. Modified Pham et al. (2005) model for Sand 2

The proposed modification can only be regarded as a first approach for the estimation of the wetting branch based on the drying curve of silty sands and should be checked by further experiments.

\section{Conclusions}

In this paper the hysteretic behaviour of two silty sands was experimentally determined. The measured SWRCs showed a hysteretic behaviour over the entire range of suction. The water content during compaction affects the behaviour of the SWRC of the tested silty sands with a fine content of $28 \%$. Compaction at decreasing water content leads to an increase of inter-aggregate pores which decreases the maximum water content measured at quasi-saturated conditions. The transition zone remains mainly unaffected. In the residual zone an increase in suction was observed with decreasing water content during compaction which cannot be satisfactorily explained but is assumed to be linked to differences of fine content between the samples tested with the WP4 devices.

The boundary drying curves were compared to the prediction of three empirical models which need the boundary drying curve as input parameter. All three models yielded reasonable results for water contents higher than the residual one. The Pham et al. (2003) model turned out to give the best results for high water contents but needs additional experimental data as input parameters. A suggestion was made to modify the Pham et al. (2005) model in order to achieve a better prediction of the wetting branch at low water contents. This modification has yet to be validated.

\section{References}

1. I.B., Donald, Proc. Of the sec. Australian-New Zealand Conf. on Soil mechanics and foundation engineering (1956)

2. N. Khalili, M. H. Khabbaz, Géotechnique, 48, No. 5, pp. 681-687, (1998).

3. S. L. Houston, J. Geotech. Geoenviron. Eng., 134, pp. 1619-1632, (2008)

4. S.K. Vanapalli, W.S. Sillers, M.D. Fredlund, $51^{\text {st }}$ Geotech. Conf., (1998)

5. D. Sheng, A. Zhou, D.G. Fredlund, Geotech. Geol. Eng., 29, pp. 145 - 159, (2011)

6. D.G. Fredlund, H. Rahardjo, M.D. Fredlund, Unsaturated Soil Mechanics in Engineering Practice, (2012)

7. H.Q. Pham, D. G. Fredlund, S. L. Barbour, Can. Geotech. J., 42, pp. 1548-1568, (2005)

8. L. M. Arya, J. F. Paris., Soil Sci. Soc. Am. J., 45, pp. 1023-1030, (1981)

9. D. M. Pedroso, D. J. Williams, Comput. Geotech., 37, No. 3, pp. 374-380, (2010)

10. H. Q. Pham, D. G. Fredlund, S. L. Barbour, Géotechnique, 53, No. 2, pp. 293-298, (2003)

11. D. G. Fredlund, D. Sheng, J. Zhao, Can. Geotech. J., 48, pp. 186-198, (2011)

12. P. Delage, 3rd Intern. Conf. on Unsat. Soils, pp. $973-$ 996, (2002)

13. D.G. Fredlund, A. Xing, Can. Geotech. J., 31, pp. 521-532, (1994)

14. E. Birle, Sec. Europ. Conf. on Unsat. Soils, pp. 145152, (2012)

15. P. Delage, M. Audiguier, Y.J. Cui, M.D. Howat, Can. Geotech. J., 33, pp. 150-159, (1996) 